\title{
Diurnal water-pressure fluctuations: timing and pattern of termination below Bench Glacier, Alaska, USA
}

\author{
T. J. FUDGE, ${ }^{1}$ Joel T. HARPER, ${ }^{2}$ Neil F. HUMPHREY, ${ }^{1}$ W. Tad PFEFFER ${ }^{3}$ \\ ${ }^{1}$ Department of Geology and Geophysics, University of Wyoming, Laramie, WY 82071-3006, USA \\ E-mail: tjfudge@uwyo.edu \\ ${ }^{2}$ Department of Geology, University of Montana, Missoula, MT 59812-1296, USA \\ ${ }^{3}$ Institute of Arctic and Alpine Research, University of Colorado, Boulder, CO 80309-0450, USA
}

\begin{abstract}
Observations from basal water-pressure sensors along the length of Bench Glacier, Alaska, USA, show that diurnal fluctuations of water pressure are seasonal and restricted to summer. Most notable about these fluctuations is their disappearance in the late summer and early autumn, long before the seasonal end of diurnal meltwater input. Here we present data documenting the end of diurnal water-pressure fluctuations during the 2002 and 2003 melt seasons. The end of diurnal fluctuations occurred abruptly in multiple boreholes spaced meters to kilometers apart. There was no obvious spatial progression of termination events, and a clear correlation with meteorological forcing or discharge in the outlet stream was not apparent. After diurnal pressure fluctuations ended, basal water pressure returned to a high, generally steady, value either in an irregular pattern or by a distinct increase. This high water pressure was interrupted by episodic, acyclic events throughout the autumn before becoming stable and high in winter.
\end{abstract}

\section{INTRODUCTION}

Subglacial drainage is commonly believed to undergo significant changes in response to seasonal variation of meltwater input (Röthlisberger and Lang, 1987; Fountain and Walder, 1998). In particular, two end-member modes of drainage are believed to exist: a winter mode and a summer mode. The summer mode is characterized by spatially varying, and often large, diurnally fluctuating water pressures (e.g. Fountain, 1994; Murray and Clarke, 1995; Gordon and others, 1998). Winter observations are rare, but limited measurements suggest that water pressures are

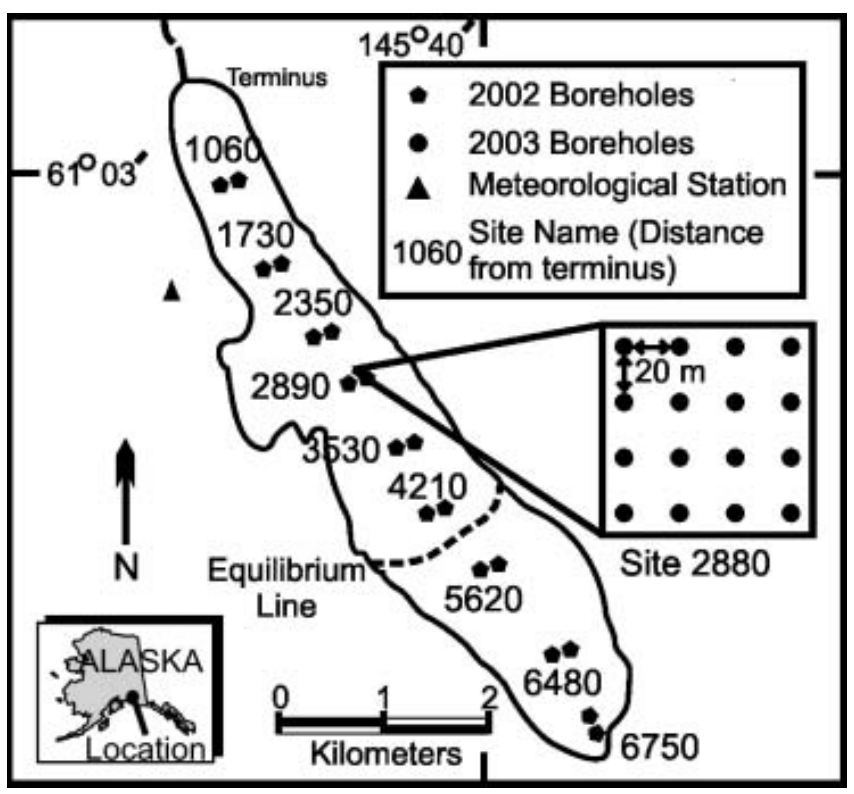

Fig. 1. Map of Bench Glacier, showing boreholes drilled in 2002 (pentagons) and 2003 (circles). The triangle shows the meteorological station adjacent to the glacier at $1300 \mathrm{~m}$ elevation (equivalent to site 2890). typically high and experience little variability (e.g. Kulessa and others, 2003; Harper and others, 2005).

Considerable research has focused on the evolution of glacier drainage from spring to summer (e.g. Gordon and others, 1998; Nienow and others, 1998; Harper and others, 2002). However, the transition of the drainage system from the summer to winter mode, typically occurring in late summer or early autumn, remains largely unstudied. In this paper, we present field observations which address this need. Our basal water-pressure measurements come from boreholes drilled to the bed at locations that span the entire length of a valley glacier. The data presented here will focus on two spatial scales: kilometer-scale measurements collected in 2002 from boreholes at nine sites along the glacier, and decameter-scale measurements collected in 2003 from an orthogonal grid of 16 boreholes with $20 \mathrm{~m}$ spacing. These records show that diurnal fluctuations in water pressure ended in a series of abrupt mid- to latesummer events. Following the end of diurnal fluctuations, water pressure remained high, with small acyclic variations. Occasional acyclic events interrupted the highpressure regime throughout the autumn, but became smaller in amplitude as the steady and high water pressure of the winter mode was established by the end of the year.

\section{FIELD SITE AND MEASUREMENTS}

Our data were collected at Bench Glacier, a temperate glacier located in the Chugach Mountains, near Valdez, Alaska, USA (Fig. 1). The glacier is roughly $7 \mathrm{~km}$ long and spans $1200 \mathrm{~m}$ vertically. It has a simple geometry, with no major tributaries, and an average surface slope of $10^{\circ}$. The equilibrium line is located approximately $4500 \mathrm{~m}$ from the terminus at $1400 \mathrm{~m}$ elevation. From borehole video imaging and drill experiments, the bed has been characterized as 'hard'. For a more detailed description of Bench Glacier and its bed see Harper and others (2005). 

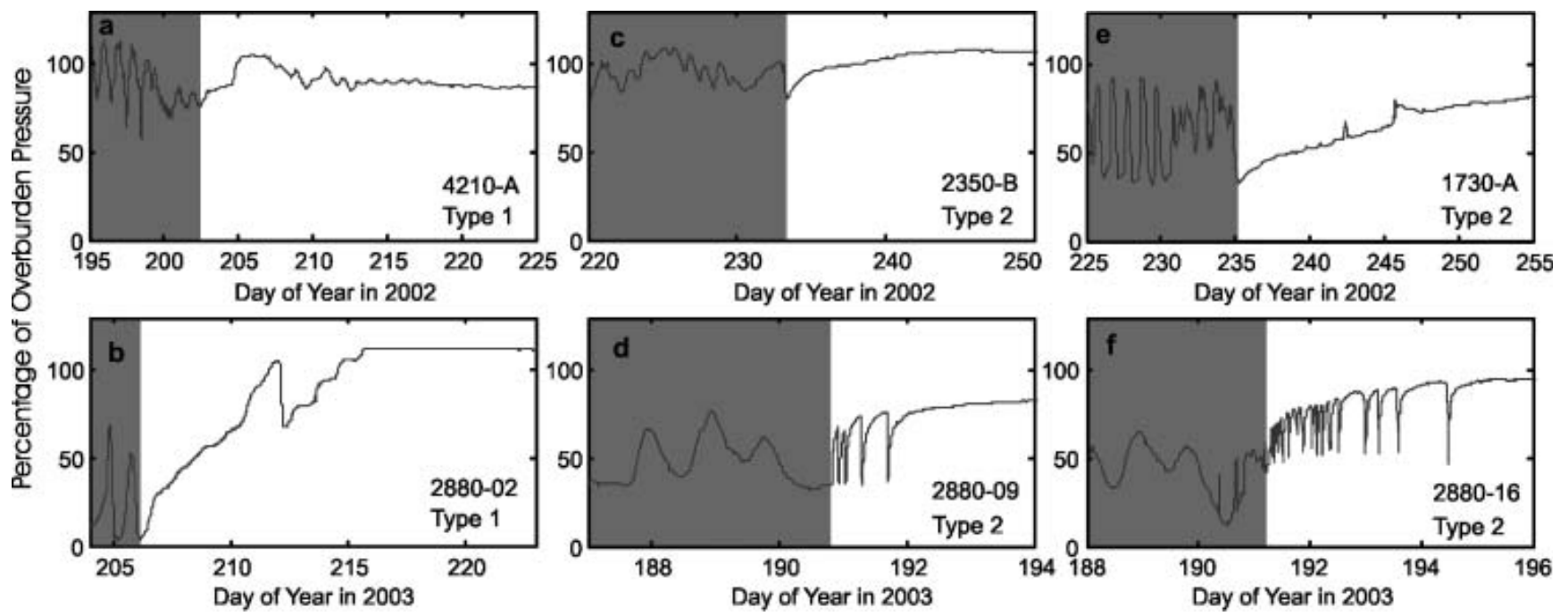

Fig. 2. Water pressure in six boreholes. Dark shading indicates diurnal period; light shading is period of irregular behavior; unshaded is the transition period.

\section{Borehole records}

The boreholes discussed in this paper were drilled on the glacier in a pattern designed to examine two spatial scales. In 2002, the kilometer scale was examined using nine pairs of boreholes at the center line along the entire length of the glacier. In 2003, the decameter scale was examined using an orthogonal grid of 16 boreholes, covering an area of $3600 \mathrm{~m}^{2}$ (20 $\mathrm{m}$ spacing) near the center of the ablation area (Fig. 1). The boreholes are labeled by the distance in meters from the terminus, and contain either the suffix ' $A$ ' for boreholes on the eastern side or ' $\mathrm{B}$ ' for boreholes on the western side. The boreholes in the grid are numbered consecutively. The boreholes were nearly vertical because the same equipment and drilling methods were used in applications where detailed inclinometry indicates this to be true (Harper and others, 1998). After drilling, boreholes were open to direct surface water input through the summer. During the winter, however, the holes closed near the surface by freezing shut and no longer remained open to surface water input.

All boreholes had sensors for measuring water pressure placed within $2 \mathrm{~m}$ of the glacier bed, and these sensors were connected by cables to data loggers at the surface. The data loggers had sufficient power and memory to record observations every few minutes for 2 years. (Time accuracy and synchronization of data logger schedules was \pm 2 hours in 2002 and $\pm 5 \mathrm{~min}$ in 2003.) Some sensors were damaged by high-pressure events (greater than twice overburden) and did not remain operational for the entire data-collection interval. These sensor-damaging 'over-pressure' events occurred in both 2002 and 2003, and will be discussed in a subsequent paper. In this paper, we refer to sensors damaged in this manner as 'offline'.

\section{Meteorological and stream records}

In 2003, a meteorological station was established at $1300 \mathrm{~m}$ elevation on a ridge above the glacier (Fig. 1). This elevation is approximately equal to the elevation of site 2890 on the glacier. Temperature, precipitation, wind speed and wind direction were measured every $10 \mathrm{~min}$ and recorded as 4 hour averages. Stage data were collected in the outlet stream of the glacier using a pressure transducer in 2003.

\section{RESULTS}

\section{Termination of diurnal water-pressure fluctuations}

Diurnal fluctuations in water pressure as large as $80 \%$ of overburden pressure were common throughout the summer in the ablation area (sites 4210 and below), but were not observed in the accumulation area. The end of diurnal fluctuations was straightforward to identify in many of the water-pressure records (e.g. Fig. 2d), but was more difficult when large pressure swings diminished into small fluctuations superimposed on larger, longer-term pressure trends (e.g. Fig. 2b). In these cases, the end of diurnal fluctuations was defined as when daily fluctuations were no longer the dominant characteristic of the record.

\section{Kilometer scale (2002)}

Diurnal water-pressure fluctuations were observed in 8 of the 12 boreholes located in the ablation area and ended during a 62 day span. Borehole 4210-B, located closest to the equilibrium-line altitude, had diurnal fluctuations terminate first, on day 202. Borehole 1060-A, located at the lowest site on the glacier, had diurnal fluctuations end on day 264, and was thus the last of the borehole sites to display the termination of diurnal fluctuations. Diurnal fluctuations in the other six boreholes terminated abruptly at two different time periods: boreholes 4210-B, 2350-A and 1730-B on days 218-219, and boreholes 2890-A, 2350-B and $1730-\mathrm{A}$ on day 230 (Table 1; Fig. 3).

\section{Decameter scale (2003)}

Diurnal fluctuations in water pressure were observed in 11 of the 16 boreholes and ended during a 38 day period. (Two boreholes, 2880-04 and 2880-17, however, went offline prior to the end of diurnal fluctuations.) A set of two boreholes terminated diurnal fluctuations on each of days 183, 189, 198-199 and 206-207 (Table 1). The diurnal pressure swings in the last borehole ended on day 220 (Fig. 4).

The end of diurnal water-pressure fluctuations in two or more boreholes within 1 day of each other is defined as a termination event. In 2003, the termination events occurred more than 1 month before the end of above-freezing daytime temperatures and did not correspond to obvious 


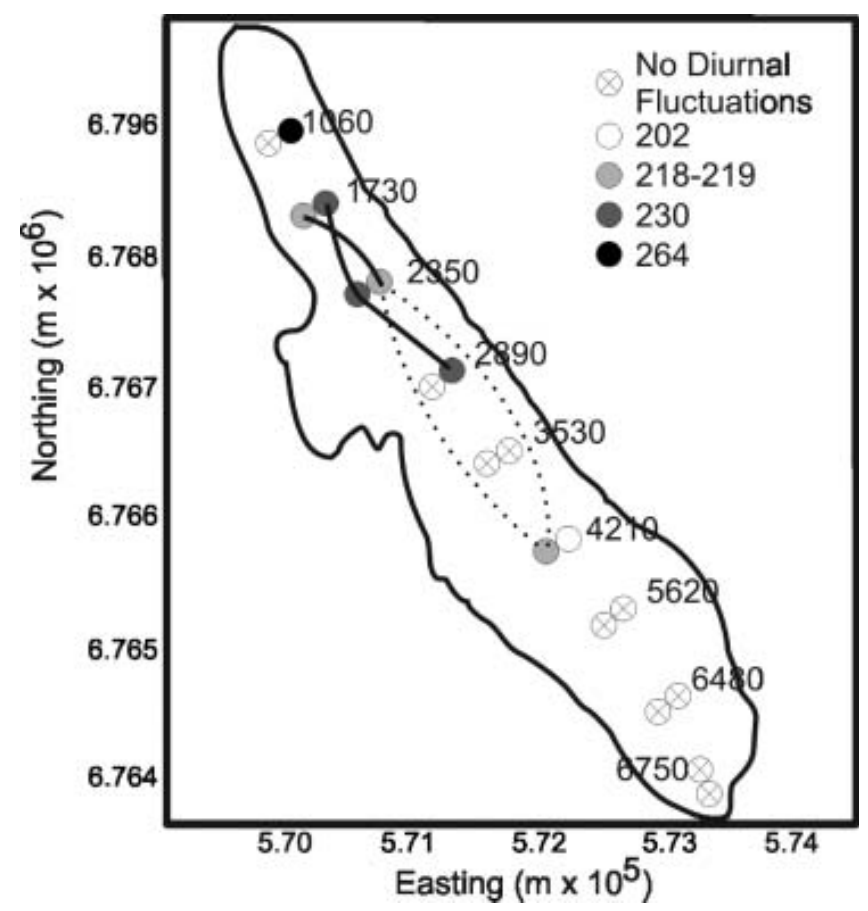

Fig. 3. Kilometer-scale distribution and timing of the termination of diurnal water-pressure fluctuations. Lines (solid and dashed) connecting boreholes of common termination events indicate that if individual channels are assumed to connect boreholes, these channels would cross between sites 1730 and 2350. Northing and easting are in Universal Transverse Mercator, Zone 6, coordinates.

meteorological forcing (Fig. 5). The meteorological data for 2002 (from Valdez, $30 \mathrm{~km}$ west and at a lower elevation) also lacked obvious forcing of termination events. The stream-stage data from 2003 (Fig. 5) show that the discharge remained high throughout the 38 day termination period and that anomalous discharges did not relate to termination events.

Table 1. Borehole termination and transition characteristics

\begin{tabular}{|c|c|c|c|c|}
\hline Borehole & $\begin{array}{c}\text { Diurnal } \\
\text { end }\end{array}$ & $\begin{array}{c}\text { Days to } \\
\text { high pressure }\end{array}$ & $\begin{array}{l}\text { Duration of } \\
\text { asymptotic } \\
\text { transition }\end{array}$ & $\begin{array}{c}\text { Failed } \\
\text { asymptotic } \\
\text { transitions }\end{array}$ \\
\hline $1060-A^{*}$ & 264 & 24 & - & - \\
\hline $1730-A^{*}$ & 230 & 34 & 30 & no \\
\hline $1730-B^{*}$ & 218 & 1 & - & - \\
\hline $2350-A^{*}$ & 219 & 33 & 13 & no \\
\hline $2350-B^{*}$ & 230 & 16 & 13 & no \\
\hline $2890-A^{*}$ & 230 & 7 & 4 & yes \\
\hline $4210-A^{*}$ & 202 & 11 & - & - \\
\hline $4210-B^{*}$ & 218 & 24 & - & - \\
\hline $2880-01^{\dagger}$ & 199 & 2 & - & - \\
\hline $2880-02^{\dagger}$ & 206 & 9 & - & - \\
\hline $2880-03^{\dagger}$ & 183 & 11 & 3 & yes \\
\hline $2880-06^{\dagger}$ & 207 & 1 & - & - \\
\hline $2880-09^{\dagger}$ & 189 & 3 & 2 & yes \\
\hline $2880-13^{\dagger}$ & 198 & 1 & 1 & no \\
\hline $2880-14^{\dagger}$ & 183 & 11 & - & - \\
\hline $2880-16^{\dagger}$ & 189 & 6 & 2 & yes \\
\hline $2880-19^{\dagger}$ & 220 & 6 & 1 & yes \\
\hline
\end{tabular}

*Kilometer scale; ${ }^{\dagger}$ decameter scale.

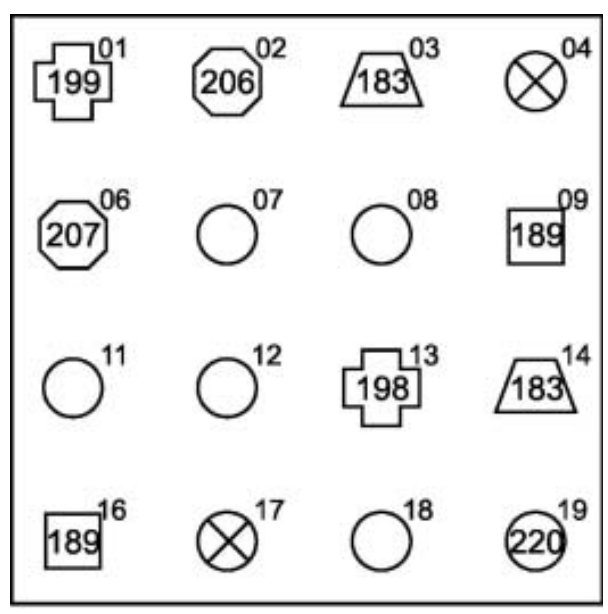

Fig. 4. Decameter-scale distribution and timing of the termination of diurnal water-pressure fluctuations in the grid area. Numbers inside shapes indicate the day of termination; shapes show boreholes of the same termination event; open circles indicate no diurnal fluctuations; and circles with a cross indicate the boreholes went offline prior to the end of diurnal fluctuations. Boreholes show no clustering of termination events. Top of box is farthest up-glacier.

\section{Establishment of the winter drainage mode}

The return to a high, stable water pressure, characteristic of the winter drainage mode, occurred in two steps. The first step was a transitional phase when water pressure became near overburden pressure and without cyclic variations. The second step was an autumn phase when acyclic pressure events appeared along the glacier's length. High water pressure is defined as above $70 \%$ of overburden pressure.

\section{Step 1: transition to high pressure}

The transition from diurnally fluctuating water pressure to a high, non-fluctuating (but sometimes varying as described below) water pressure occurred in two principal ways: type 1 and type 2 transitions. Type 1 transitions were irregular and did not have a distinct or abrupt transition event. They occurred in half of the boreholes, and examples are shown in Figure $2 \mathrm{a}$ and $\mathrm{b}$. Where the water pressure was initially low $(<70 \%$ of overburden pressure), the pressure rose irregularly, often with a slight diurnal influence, until a stable high water pressure was reached (e.g. Fig. 2b). Where the water pressure was already high, there was a period of minor irregularity which dampened to a steady high pressure (e.g. Fig. 2a).

Type 2 transitions are distinguished by a distinct event and characterized by an asymptotic approach to a final high pressure (e.g. Fig. 4c-f). These asymptotic transitions had durations of 1 day to several weeks, and pressure increases of $20-65 \%$ of overburden. They either quickly followed the end of diurnal fluctuations (e.g. Fig. 2d) or began after a short period (1-5 days) of irregular behavior (e.g. Fig. 2c, e and f). Type 2 transitions started from a wide range of water pressures, $35-80 \%$ of overburden, and generally began at or near local pressure minimums (e.g. Fig. 2c-e). The asymptotic transitions are not unique to Bench Glacier, as Fountain (1994) shows similar examples in two boreholes at South Cascade Glacier, Washington, USA.

A common feature observed in half of the asymptotic transitions was a large, abrupt fall in water pressure before a final stable pressure was reached (e.g. Fig. $4 d$ and f). The 


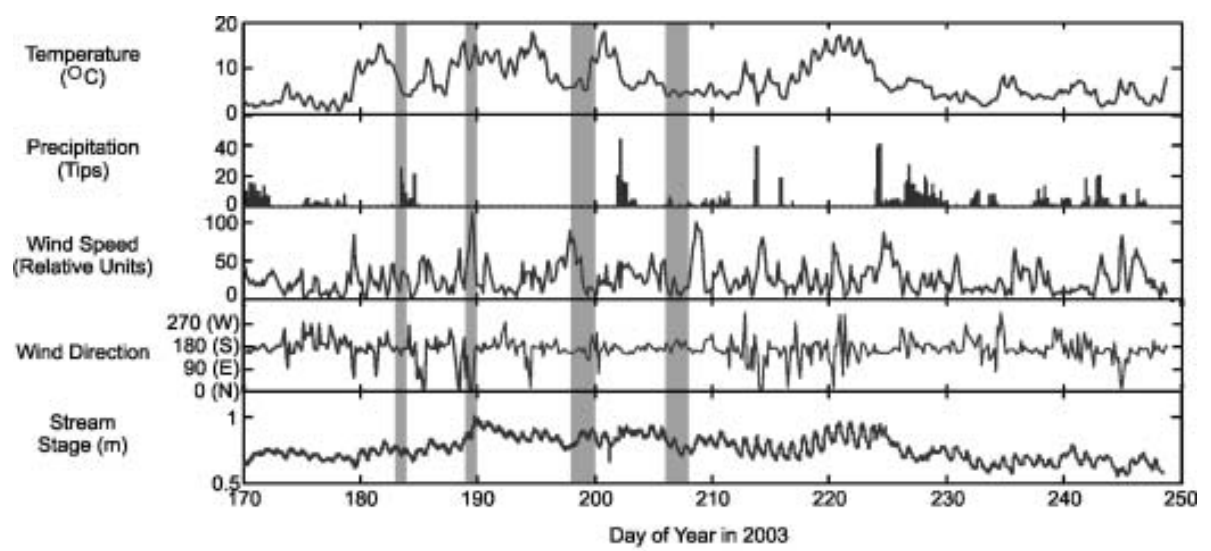

Fig. 5. Meteorological data and stream stage collected in 2003. Gray bars show days of termination events.

similarity of these abrupt but abortive features to the type 2 transitions discussed above leads us to speculate that these represent 'failed type 2 transitions' in which conditions necessary to complete the transition were not apparently satisfied. These failed transitions were repeated as many as 16 times before the final asymptotic transition. All failed asymptotic transitions and the final transition had short durations of 5 hours to 4 days.

\section{Step 2: autumn phase}

Throughout the autumn, occasional acyclic events interrupted the generally stable, high water pressure at boreholes along the length of the glacier. In one particular event, on days $266-272$, a pressure rise of $5-15 \%$ of overburden, followed by a pressure decline of $20-40 \%$ of overburden, was observed at four sites (Fig. 6). The event was not experienced synchronously at all boreholes, and there was no simple up- or down-glacier propagation. We were not able to identify its cause. The autumn phase had no distinct end as the frequency and magnitude of events slowly diminished. The water pressure had become high and steady by the end of the year.

\section{DISCUSSION AND CONCLUSION}

The boreholes involved in termination events did not demonstrate simple spatial relationships. If we assume the boreholes of each termination event are connected by individual drainage channels, the events show an interweaving spatial pattern at both large and small scales. The large-scale pattern is illustrated by Figure 3, where the propagation from borehole to borehole of the two termination events clearly 'crosses' between sites 1730 and 2350. Hence, individual channels connecting the boreholes cannot be assumed. At the small scale, the distribution of boreholes in each event also suggests it is unlikely that termination groupings represent isolated drainage systems. Thus, observations during the waning stages of the melt season show that components of a common drainage system ended diurnal fluctuations in distinct events that spanned decameter to kilometer scales.

The timing of the termination events also suggests that the drainage system changed in discrete steps. Diurnal fluctuations continued in other parameters of the hydrology system well after the first termination event had occurred. For example, diurnal fluctuations in water pressure continued in other boreholes, the stream stage continued to fluctuate diurnally for at least another month, and meteorological data and field observations showed meltwater production continued on a waning diurnal cycle. The strong diurnal character of these three parameters implies that the glacier hydrology system was channelized (Fountain and Walder, 1998), allowing the rapid transport of surface meltwater to the outlet stream. Since the termination events occurred while active drainage channels still existed, our data recorded a step-wise collapse of the drainage system. The boreholes likely sampled areas of the bed not within main channels but connected to them through smaller conduits or cavities.

The specific cause of the termination events is unclear. The timing of the events did not correspond to obvious meteorological triggers, such as anomalously high or low temperatures, rainfalls or wind speeds. Further, they occurred while strong diurnal melt cycles were present. This suggests that the termination events resulted from gradual changes in the temporal and spatial production and routing of meltwater. As the length of the day shortened during the summer, there was not only less meltwater production, but also longer periods with little or no water input. These combined effects allowed for increased closure of connections to the main drainage channels. Additionally, spatial changes in both the production and routing of meltwater may have occurred throughout the summer. Such changes could have resulted from varying meltwater production caused by shading effects from the changing angle of the sun. Also, stream capture and rerouting of water both at the

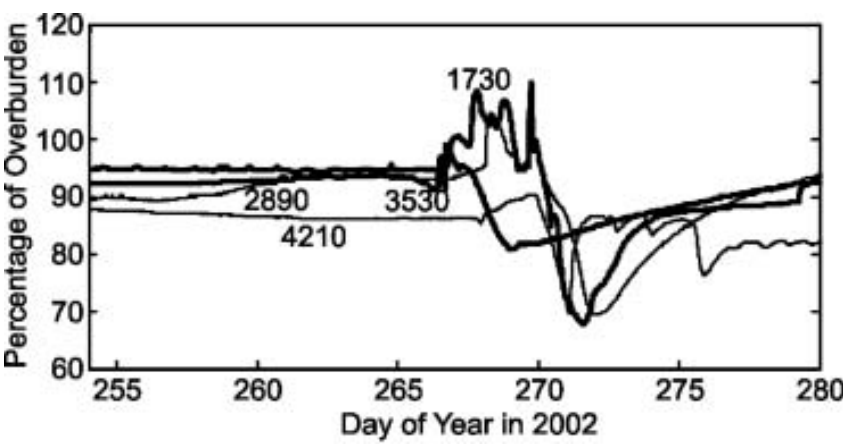

Fig. 6. Example autumn event experienced at four sites along the glacier. 
surface and at the bed could have caused areas of the glacier to detach from the channelized drainage system. Interestingly, the outlet stream stage remained consistent throughout the termination period, which suggests the water flux averaged over the bed did not change significantly.

The termination events indicate a step-wise or non-linear response in the drainage system to the slow waning of the water-input forcing. This response is likely the instability in transient conduit flow noted by Nye (1976) and Spring and Hutter (1981) where the closure of a conduit system can accelerate rapidly below some threshold water flux. However, the groupings of multiple boreholes during a termination event indicate that the governing process is more complicated because the drainage system response is also patchy and step-wise in space. We observed both connectivity in boreholes kilometers apart on the glacier and a lack of connectivity in boreholes spaced $20-60 \mathrm{~m}$ apart. This implies that the driving mechanism has both global and local features. Changes in the main drainage system likely trigger events along the length of the glacier, but the response of individual boreholes seems to depend on local conditions.

\section{REFERENCES}

Fountain, A.G. 1994. Borehole water-level variations and implications for the subglacial hydraulics of South Cascade Glacier, Washington State, U.S.A. J. Glaciol., 40(135), 293-304.

Fountain, A.G. and J.S. Walder. 1998. Water flow through temperate glaciers. Rev. Geophys., 36(3), 299-328.
Gordon, S., M. Sharp, B. Hubbard, C. Smart, B. Ketterling and I. Willis. 1998. Seasonal reorganization of subglacial drainage inferred from measurements in boreholes. Hydrol. Process., 12(1), 105-133.

Harper, J.T., N.F. Humphrey and W.T. Pfeffer. 1998. Threedimensional deformation measured in an Alaskan glacier. Science, 281(5381), 1340-1342.

Harper, J.T., N.F. Humphrey and M.C. Greenwood. 2002. Basal conditions and glacier motion during the winter/spring transition, Worthington Glacier, Alaska, U.S.A. J. Glaciol., 48(160), 42-50.

Harper, J.T., N.F. Humphrey, W.T. Pfeffer, T. Fudge and S. O'Neel. 2005. Evolution of subglacial water pressure along a glacier's length. Ann. Glaciol., 40 (see paper in this volume).

Kulessa, B., B. Hubbard, G.H. Brown and J. Becker. 2003. Earth tide forcing of glacier drainage. Geophys. Res. Lett., 30(1), 1011. (10.1029/2002GL015303.)

Murray, T. and G.K.C. Clarke. 1995. Black-box modeling of the subglacial water system. J. Geophys. Res., 100(B7), 10,23110,245

Nienow, P., M. Sharp and I. Willis. 1998. Seasonal changes in the morphology of the subglacial drainage system, Haut Glacier d'Arolla, Switzerland. Earth Surf. Process. Landforms, 23(9), 825-843.

Nye, J.F. 1976. Water flow in glaciers: jökulhlaups, tunnels and veins. J. Glaciol., 17(76), 181-207.

Röthlisberger, H. and H. Lang. 1987. Glacial hydrology. In Gurnell, A.M. and M.J. Clark, eds. Glacio-fluvial sediment transfer: an alpine perspective. Chichester, etc., Wiley, 207-284.

Spring, U. and K. Hutter. 1981. Numerical studies of jökulhlaups. Cold Reg. Sci. Technol., 4(3), 227-244. 